Since our parent Association, the AATS, underwrites all operational costs of the Foundation, $100 \%$ of all individuals' contributions to go directly to Foundation programming. The AATS Graham Research Foundation is driving leadership, learning, and innovation in the pursuit of excellence!

For more information on the AATS Graham Foundation, please visit http://aatsgrahamfoundation.org.

\section{Edwards Lifesciences Advanced Treatments of Valve Disease Fellowship}

The Edwards Lifesciences Advanced Treatments of Valve Disease Fellowship provides an educational experience for a young cardiothoracic surgeon to spend a period of three months (minimum) to one year studying clinical techniques at a secondary institution with a focus on enhancing expertise in advanced treatments of valve disease. A $\$ 25,000$ award will be provided to a successful applicant to help defray related travel and living expenses incurred at the secondary institution.

For additional information regarding the Fellowship please visit the AATS Graham Foundation Web site at www.AATSGrahamFoundation.org. Interested applicants should meet the following qualifications before applying:

- A candidate should have completed his/her formal training in general surgery and in thoracic and/or cardiovascular surgery, but should yet not have reached a senior position.

- Candidate meets all necessary criteria (license, visa, etc) for travel to and from secondary center

- Candidates must have a current academic or hospital appointment

- Candidates must be in their first five years after CT training

Applications for consideration must be submitted electronically by November 1, 2014. Applications will be reviewed by the AATS Graham Foundation's Scientific Review Committee, which includes surgeons with recognized expertise in the treatment of valve disease. Applications will be graded on all aspects of the award criteria and notified of the decision by December 15th.

\section{Ethicon Fellowship for Advanced Thoracic Minimally Invasive Surgery}

The AATS Graham Foundation Ethicon Fellowship for Advanced Thoracic MIS provides an educational experience for young thoracic surgeons from the United States to spend a focused period of time between three months and one year time to study clinical techniques at a host institution proficient in MIS. The program is primarily geared to provide an opportunity to obtain expertise in advanced treatments of minimally invasive surgery, such as lung resection surgery.

For additional information regarding the Fellowship, please visit the AATS Graham Foundation Web site at www.AATSGrahamFoundation.org. Interested applicants should meet the following qualifications before applying:

- A candidate should have completed his/her formal training in general surgery and in thoracic and/or cardiovascular surgery, but should yet not have started a staff position or have started a staff position within a 12-month period prior to commencing this fellowship.

- Candidate meets all necessary criteria (license, visa, etc) for travel to and from secondary center

- Candidates must have a current academic or hospital appointment

- Candidates must be in their first five years after thoracic training

\section{Application Process}

Applications will be available annually with a deadline of November 1st. In addition to a formal online application, candidates will also be required to upload the following materials:

- Curriculum vitae

- Letter of support from their home and secondary institutions

- Detailed outline of plans for the duration of stay at secondary center

- One page narrative on what they hope to accomplish during their travel to a secondary training center

- One page statement of future career goals

- One page statement describing the relationship of the planned study to the applicant's prior work, preparation and professional goals

Applications for consideration must be submitted electronically by November 1, 2014. Applications will be reviewed by the AATS Graham Foundation's Scientific Review Committee, which includes surgeons with recognized expertise in minimally invasive surgery and the focus will be to place the recipients in institutions using Ethicon technology for MIS. Notifications of the final decision will be provided by December 15th. 